\title{
Disturbance-dependent spatial distribution of sexes in a gynodioecious understory shrub
}

\author{
Antonio R. Castilla ${ }^{\mathrm{a}, *}$, Thorsten Wiegand ${ }^{\mathrm{b}}$, Conchita Alonso ${ }^{\mathrm{a}}$, Carlos M. Herrera ${ }^{\mathrm{a}}$ \\ ${ }^{a}$ Estación Biológica de Doñana, Consejo Superior de Investigaciones Científicas (CSIC), Avenida Américo Vespucio s/n, E-41092 Sevilla, \\ Spain \\ ${ }^{\mathrm{b}}$ UFZ Helmholtz Centre for Environmental Research-UFZ, Department of Ecological Modelling, Permoserstr. 15, 04318 Leipzig, Germany
}

\begin{abstract}
Several ecological conditions and processes occurring naturally in plant populations may lead to spatial aggregation of sexes within populations of sexually polymorphic species. In addition, ecological disturbances such as forest management or fire could also affect the spatial distribution of sexes within populations. Spatial aggregation of sexes can have important consequences for the fitness of the individuals in sex-biased patches through increased pollen limitation and/or variation in the male fitness of hermaphrodites. Therefore, spatial aggregation of sexes could be relevant for the maintenance of the sexual polymorphism in plant species. Here, we used point pattern analysis to study the spatial distribution of female and hermaphrodite individuals within a single population of the gynodioecious understory shrub Daphne laureola, inhabiting a young pine reforestation and the adjacent natural undisturbed area. In the undisturbed area, we found that hermaphrodites were distributed randomly whereas females were spatially aggregated at short distances. Such aggregation could result from narrower ecological amplitude, cytonuclear determination of sex and limited dispersal and/or increased cloning in females. In the reforested area, females were slightly more abundant and the two sexes were randomly distributed among all plants. Recolonization processes after certain forest disturbances could thus favour the establishment of females and alter the spatial distribution of sexes in this understory species.
\end{abstract}

\section{Zusammenfassung}

Verschiedene in Pflanzenpopulationen natürlich vorkommende ökologische Bedingungen und Prozesse können zu einer räumlichen Klumpung von Geschlechtern innerhalb von Populationen sexuell polymorpher Arten führen. Darüber hinaus können Störungen wie forstwirtschaftliche Maßnahmen oder Brände infolge stärkerer Pollenbeschränkungen bzw. Veränderungen der männlichen Ausprägung von Hermaphroditen schwerwiegende Folgen für die Fitness von Individuen in Vorkommen haben bei denen ein Geschlecht überwiegt. Das heißt, die räumliche Klumpung der Geschlechter könnte für die Erhaltung des sexuellen Polymorphismus von Pflanzenarten von ausschlaggebender Bedeutung sein. Mittels der Punktmusteranalyse (PPA) haben wir die räumliche Verteilung von weiblichen und zwittrigen Pflanzen innerhalb einer Population des unterwuchsbildenden LorbeerSeidelbasts (Daphne laureola) in einer jungen Kiefernschonung sowie einer benachbarten naturbelassenen Fläche untersucht. Auf der naturbelassenen Fläche waren die zwittrigen Pflanzen zufällig verteilt, während die weiblichen Pflanzen in kurzen Abständen räumliche Klumpung aufwiesen. Diese Klumpung kann das Ergebnis einer geringeren ökologischen Amplitude, einer zytonuklearen Geschlechterfestlegung sowie einer begrenzten Verbreitung bzw. eines verstärkten Klonens bei weiblichen

\footnotetext{
${ }^{*}$ Corresponding author. Tel.: +34 954466700; fax: +34 954621125.

E-mail address: acastilla@ebd.csic.es (A.R. Castilla).
} 
Pflanzen sein. In der Schonung wurden geringfügig mehr weibliche Pflanzen festgestellt, und die beiden Geschlechtsausprägungen waren zufällig über die gesamte Population verteilt. Damit könnten Wiederbesiedlungsprozesse nach bestimmten Störungen in Waldgebieten zu einer verstärkten Ausbreitung von weiblichen Pflanzen führen und die räumliche Verteilung der Geschlechter bei dieser Unterbewuchsart verändern.

Published by Elsevier GmbH.

Keywords: Daphne laureola; Disturbances; Gynodioecy; Point pattern analysis; Spatial aggregation of the sexes

\section{Introduction}

Plant ecologists hold an enduring interest on spatial patterns within natural plant communities (Franklin 2010; Greig-Smith 1983; Pielou 1968; Watt 1947). In sessile organisms like plants, the spatial distribution of individuals within populations establishes the biotic (e.g., pollination, herbivory, intra- and interspecific competition) and abiotic (water, nutrients, light) context in which they live and thus determines their survival and reproductive success. In turn, biotic and abiotic conditions also affect the spatial distribution of individuals, so that the resulting spatial distributions carry information about the processes which operated in the past (McIntire \& Fajardo 2009; Wiegand, Jeltsch, Hanski, \& Grimm 2003; Wiegand, Martinez, \& Huth 2009). One approach for testing assumptions about these underlying processes is to contrast the observed spatial pattern with null models derived from specific ecological scenarios taking into account the locations of all mapped individuals (Schurr, Bossdorf, Milton, \& Schumacher 2004; Wiegand \& Moloney 2004). The general framework for this is provided by point pattern analysis, a set of tools for analysing the spatial distribution of discrete points (Diggle 2003; Illian, Penttinen, Stoyan \& Stoyan 2008; Ripley 1981; Stoyan \& Stoyan 1994). In some cases, additional information, such as the qualitative marks "surviving" vs. "dead", is available to characterize the points. In these cases, the interest is to find out if the process that generated the marks acted in a spatially non-random way over all points (Goreaud \& Pélissier 2003; Wiegand \& Moloney 2004).

In many dioecious and subdioecious plants the sexes are spatially aggregated within populations and their frequencies often vary along some environmental gradient (Eppley 2005; Freeman, Klikoff, \& Harper 1976 and references therein). However, spatial distribution of sexes has been less intensively studied in gynodioecious species, i.e., hermaphrodites and females coexisting within a single population. For instance, El-Klebawy and Freeman (1999) and Graff (1999) used nearest neighbour analyses to explore segregation of sexes. Other studies used Moran's I to determine the degree of spatial autocorrelation in sexes (Laporte, Viard, Bena, Valero \& Cuguen 2001; Olson, Graff \& Niles 2006; Van Etten \& Chang 2009). In contrast to Moran's I, which is adapted to a data structure where the points are sampling points of an underlying continuous variable, the marks of a point pattern are given only at the points and are undefined otherwise (Illian et al. 2008: p. 344). Thus, marked point pattern analysis is especially adapted to data comprising the mapped locations of plants and an attached mark specifying a certain feature of the plant.

Most studies using other methods than marked point pattern analysis revealed that gynodioecious species frequently present spatial aggregation of sexes within populations (e.g., Graff 1999; Laporte et al. 2001; Olson et al. 2006; Van Etten \& Chang 2009). The extent of this spatial aggregation varies among species and populations within species, ranging from immediate neighbourhood (e.g., few meters; Graff 1999) to larger distances (e.g., tens of meters; Laporte et al. 2001). Small-scale spatial aggregation of female individuals has been frequently interpreted as evidence of cyto-nuclear determination of sex because the maternal component of male sterility inheritance combined with limited seed dispersal could lead to spatial aggregation of female individuals within populations (De Cauwer, Dufay, Fuguen, \& Arnaud 2010; McCauley \& Bailey 2009). Alternatively, spatial aggregation of sexes within populations could be related to sex-associated differential germination and/or mortality related to microenvironmental conditions (El-Klebawy \& Freeman 1999; Van Etten \& Chang 2009). Whatever the causal mechanisms, spatial aggregation of the sexes may have important consequences for the fitness of the individuals through several processes such as increased pollen limitation for aggregated females (Graff 1999; Olson et al. 2006), increased selfing rates of hermaphrodites with decreased hermaphrodite frequency (Miyake \& Olson 2009) or improved male fitness in hermaphrodites within female biased clusters (De Cauwer et al. 2010).

In addition to natural variation in the biotic and/or abiotic context within populations, ecological disturbances introduce changes that could affect differentially plants with different sex, leading to sex-biased disturbed areas (McCauley \& Bailey 2009). The relevant role of ecological disturbances promoting the establishment of female individuals is widely recognized, although only two studies have analysed this phenomena in pioneer species (De Cauwer et al. 2010; Manicacci, Couvet, Belhassen, Gouyon \& Atlans 1996). Both studies found that females were more abundant in disturbed areas because of their higher seed production. In addition, they found that founder events led to stronger local cytoplasmic determination of sex and thus to the existence of large patches of females.

Forest management treatments can be understood as disturbances that may have a large influence on the composition, structure and biodiversity of the forests (Bengtsson, Nilsson, 
Franc, \& Menozzi 2000; Niemelä 1999). Higher species diversity in non-disturbed forests than in forest plantations is related to their higher structural complexity, both in canopy and understory, which favours greater habitat and environmental heterogeneity (Crow, Buckley, Nauertz, \& Zasada 2002; Valladares \& Gianoli 2007). Light is commonly considered to be the major limiting factor of forest vegetation cover and/or richness (Bazzaz 1990; Hill 1979; Jennings, Brown, \& Sheil 1999; Kirby 1988). Understory light is closely dependent on the canopy structure (Barbier, Gosselin, \& Balandier 2008). Therefore, we can expect that intensive forest plantations lead to drastic reduction and homogenization of the light environment of the understory. In fact, numerous studies have pointed out the negative effect of tree abundance on understory cover or diversity (Alaback \& Herman 1988; Barbier et al. 2008; Thomas, Halpern, Falk, Liguori, \& Austin 1999). This kind of anthropogenic disturbance may be especially relevant in Mediterranean ecosystems characterized by sharp spatially and temporally variability in the light environment of the understory, a feature that has been shown relevant for the ecological niche segregation of plant species (Valladares, Aranda, \& Sánchez-Gómez 2004).

In the southern Iberian Peninsula, most populations of the understory shrub Daphne laureola are gynodioecious (Alonso, Mutikainen \& Herrera 2007). Within populations, increased canopy cover lead to greater pollination success in females but not in hermaphrodites individuals (Alonso \& Herrera 2008). In addition, studies using an interpopulation approach have shown the relevance of abiotic factors (e.g., temperature, precipitation) determining the relative abundance of each sex within populations (Alonso \& Herrera 2001; Alonso et al. 2007). All these biotic and abiotic factors could affect the spatial distribution of sexes within $D$. laureola populations.

In this study, we conducted a detailed small-scale analysis of the spatially explicit distribution of sexes within a southern Iberian population of $D$. laureola and compared the patterns resulting from undisturbed and disturbed areas, using techniques of marked point pattern analysis (Illian et al. 2008; Stoyan \& Stoyan 1994; Wiegand \& Moloney 2004). More specifically, we addressed the following questions: (a) are female and hermaphrodite $D$. laureola individuals spatially aggregated within-populations? (b) is the female frequency larger in the disturbed area? and (c) do environmental perturbations affect to spatial patterns of hermaphrodite and female individuals?

\section{Material and methods}

\section{Study species}

D. laureola L. (Thymelaeaceae) is an evergreen shrub that grows in the understory of coniferous and mixed mountain forests. The species flowers in winter and the pollen beetle Meligethes elongatus Rosenhauer and, to a much smaller extent, small solitary bees and noctuid moths are its main pollinators in south-eastern Spanish populations (Alonso 2004). Single-seeded black drupes ripen in June and are dispersed by several bird species (Hulme 1992; Obeso 1985). The genetic basis of gender inheritance in this species is currently unknown.

\section{Study population and habitat characteristics}

The study was focused on a large population located in the south-eastern Iberian Peninsula (Valdecuevas hereafter). This study population is located at 1380 m.a.s.l. in the Sierra de Cazorla (Jaén province), a mountainous area where the species is abundant and widespread (Castilla, Alonso \& Herrera 2011). The study population had $>2000$ reproductive individuals and a female frequency of $26 \%$. These values of altitude and female frequency are similar to the overall species' averaged values in the southern Iberian Peninsula (1450 m.a.s.l. and $29.2 \%, N=111$ populations; data not shown). While most of the study site has not been managed in the last few decades, one part of the site was reforested with pine Pinus nigra J.F. Arnold. Reforestation age was estimated using a dendrochronological analysis of cores obtained from ten dominant pine trees along a linear transect crossing over the reforestation. The sampled trees fell into two different age-classes, 45 and 35 years, indicative of a second plantation event after ten years but without signs of further maintenance treatments. The $D$. laureola subpopulation in the reforested area resulted probably from recolonization after the second pine plantation, provided that seedlings develop very slowly and only reach their reproductive stage after more than ten years (C.A. personal observation).

We expected that differences in habitat conditions, mainly light availability (see below; Appendix A: Fig. 1) could lead to different spatial patterns in the younger $D$. laureola subpopulation under the planted pines and the mature subpopulation under the undisturbed forest. To study this possibility it would have been interesting to replicate the spatial analysis of contrasting habitats in several populations, however, we did not find other nearby populations with adjacent reforested and undisturbed subpopulations of similar size and altitude, to become a replicate of the study. Therefore, we focused on the Valdecuevas population and selected a continuous area of 3.92 ha, which included both habitats, the undisturbed forest and the reforested zone, with $N=240$ individuals. All flowering individuals within that area were tagged and mapped by triangulation using a laser distance metre Leica DISTO ${ }^{\mathrm{TM}}$ A5. The sex of each individual was recorded, and the frequency of females per habitat type was estimated. Female and hermaphrodite individuals flower at the same time in the populations, and as far as we know, there is no evidence supporting sexual difference in age at first flowering. A map based on individual coordinates was displayed on a Cartesian plane using ArcGIS 9.3 (Fig. 1). 

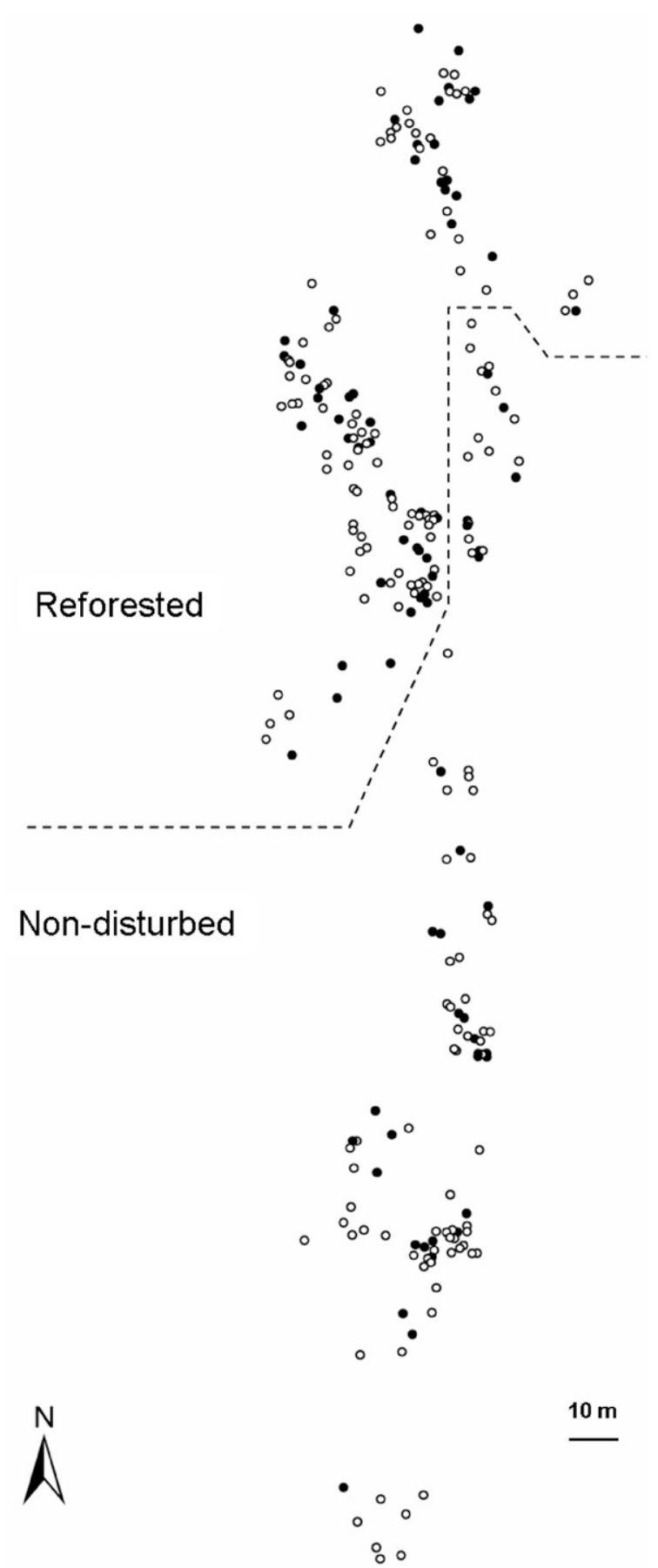

Fig. 1. Spatial distribution of sampled individual Daphne laureola plants. Black and white dots represent the positions of female and hermaphrodite individuals, respectively.

We quantified, for thirty randomly chosen trees in each subpopulation, the distance to four nearest tree neighbours (distance among canopy trees, hereafter). In the reforested habitat all the trees were pines, whereas in the undisturbed habitat there were several evergreen and deciduous tree species. Light availability in the understory was estimated with a Quantum Sensor LI-190SA (LI-COR, Nebraska, USA) along five $15-\mathrm{m}$ transects with $1 \mathrm{~m} \times 1 \mathrm{~m}$ sampling plots every $3 \mathrm{~m}$ in each subpopulation. Differences between reforested and undisturbed subpopulations in distance among canopy trees and PAR were tested using a generalized linear models including PAR and distance among canopy trees as dependent variables and subpopulation as the only fixed explanatory factor (Procedure GENMOD; SAS Institute 2002). Both dependent variables were modelled using the negative binomial distribution.

\section{Spatial analyses}

Our data comprised the spatial locations of all female and hermaphrodite individuals within the selected area at Valdecuevas (Fig. 1). We tested for differences in the average female percentage between undisturbed and reforested areas with $X^{2}$-test (108 and 132 reproductive individuals respectively).

We used techniques of marked point pattern analysis (Goreaud \& Pélissier 2003; Jacquemyn, Endels, Honnay \& Wiegand 2010) to find out if female (or hermaphrodite) individuals showed a non-random spatial pattern within all individuals. To this end, we used univariate and bivariate pair correlation functions to quantify the observed spatial patterns of female and hermaphrodite individuals within the selected area (Stoyan \& Stoyan 1994; Wiegand \& Moloney 2004). We will indicate female individuals with the subscript " 1 " (i.e., type 1 points) and hermaphrodites with the subscript "2" (i.e., type 2 points), and the joined pattern of females and hermaphrodites with subscript " $1+2$ ". The bivariate pair correlation function $g_{12}(r)$ can be defined as the expected density of type 2 points in a ring of radius $r$ and width $d r$ centred in an arbitrary type 1 point, divided by the intensity $\lambda_{2}$ of the pattern of type 2 points (i.e., the number of type 2 points divided by the area of the study region; Wiegand \& Moloney 2004). The univariate pair correlation functions $g_{11}(r)$ and $g_{22}(r)$ for female and hermaphrodite individuals, respectively, are obtained analogously by estimating the density of further type 1 or type 2 points around type 1 or type 2 points, respectively.

To detect non-random spatial patterns of females (or hermaphrodite plants) within the entire population (females plus hermaphrodites) the null model of random labelling is required (Goreaud \& Pélissier 2003; Jacquemyn et al. 2010). This null model assumes that female plants are a random sample of all plants. To quantify departures from random labelling, we contrasted test statistics of the observed data based on pair correlation functions to that expected from Monte Carlo simulations of the random labelling null model. The tests of random labelling were conducted by computing a test statistic from the observed data [e.g., $g_{11}(r)$ ], then randomly re-sampling 999 sets of females from the joined pattern of female and hermaphrodite plants and calculating the summary statistics for each simulated data set. Approximate (two-side) 95\% simulation envelopes were created by calculating for each distance $r$ the 25th lowest and highest 
values of a test statistic from the simulations of the null model. This yields an approximate 5\% error rate. However, the simulation envelopes cannot be interpreted as confidence intervals because the null hypothesis is tested simultaneously at many scales, inflating the chance of type I error. We therefore examined the significance levels over a distance interval of interest (0-25 m) using a goodness-of-fit test (Diggle 2003; Loosmore \& Ford 2006).

Because departures from random labelling may occur in many ways, we used several test statistics based on pair correlation functions which are sensitive to different biological effects (Jacquemyn et al. 2010). We used the test statistic $g_{11}(r)$ to find out if the pattern of females was aggregated within the pattern of all plants. In this case the $g_{11}(r)$ will be above the simulation envelopes. Analogously, the summary statistic $g_{22}(r)$ evaluated the distribution of hermaphrodite plants within all plants. We used the statistic $g_{11}(r)-g_{22}(r)$ to detect if the spatial pattern of female plants was more or less aggregated than that of hermaphrodites. Values $g_{11}(r)-g_{22}(r)$ above the simulation envelopes indicate a more aggregated pattern in females.

Finally, to test for density-dependent effects we used the difference $g_{1,1+2}(r)-g_{2,1+2}(r)$ (Yu, Wiegand, Yang, \& Ci 2009) that compares the density of plants around female individuals (pattern 1) with the corresponding density of plants around hermaphrodite individuals (pattern 2). The expected value of this test statistic is zero under random labelling. However, we expected positive values when female individuals were surrounded at distance $r$ on average by more plants than hermaphrodites and negative values for the opposite pattern. Note that using several statistical tests to detect departures from random labelling is an advantage because there are several ways in which such departures may occur and not all may be detected by the same test (Jacquemyn et al. 2010).

We conducted the analyses for the subpopulations in undisturbed and reforested areas separately. Thus, individuals located in the reforested area did not influence the spatial patterns of individuals in the undisturbed area and vice versa. All analyses were carried out using the software Programita for point spatial pattern analysis (Wiegand \& Moloney 2004) using the Ohser-Mücklich estimator of the pair correlation function with a box kernel with bandwidth of $0.3 \mathrm{~m}$ (Illian et al. 2008). Details on the estimators of the pair-correlation function and edge correction can be found in Illian et al. (2008, p. 194 and section 4.33).

\section{Results}

\section{Light environment in the understory}

In the undisturbed habitat there were several evergreen and deciduous tree species with longer and more variable distances among them $\left(F_{1,58}=63.47, p<0.0001\right.$; Table 1$)$. Reforested and undisturbed habitats differ also in the light environment in the understory $\left(F_{1,58}=157.63, p<0.0001\right.$; Table 1). Photosyntetically active radiation was higher and more variable in undisturbed than in reforested habitats (Table 1).

\section{Spatial patterns in hermaphrodite and female individuals}

In the undisturbed area we found that the spatial pattern of females differed significantly from the expected pattern by random labelling (Table 2 and Fig. 2). Female plants were aggregated at distances around $2.5 \mathrm{~m}$ as depicted by the statistic $g_{11}$ (Fig. 2A). Consequently, the goodness-of-fit test for the distance interval $0-25 \mathrm{~m}$ indicated a significant departure in the test statistic $g_{11}(r)$ from the null model ( $p=0.04$ ). In contrast, the pattern of hermaphrodites did not differ from patterns expected by the null model in any distance radius although they showed a tendency to be less aggregated than expected by random labelling (Fig. 2B; $p=0.089$ ). The small-scale aggregation of females caused also significant departures from the null model in the test statistics $g_{11}-g_{22}$ (Fig. 2C; $p=0.025$ ), indicating the females were at small distances around $2.5 \mathrm{~m}$ more aggregated than hermaphrodites. Furthermore, at distances around $2.5 \mathrm{~m}$ the observed values of the test statistic $g_{1,1+2}-g_{2,1+2}$ were larger than the expectation under random labelling (Fig. 2D), suggesting that females, within these distances, were located in areas of higher plant density than hermaphrodites. In fact, for distances larger than $2.5 \mathrm{~m}$, the test statistics $g_{1,1+2}-g_{2,1+2}$ and $g_{11}-g_{22}$ were very close to the theoretical expectation of zero under the null model of random labelling.

Table 1. Average values and coefficients of variation (CV) of distance among canopy trees and light availability in the understory of undisturbed and reforested habitats. Distance among canopy trees was estimated for thirty randomly chosen trees in each habitat measuring the distance to the four nearest tree neighbours. Light availability in the understory of each habitat was estimated by the photosynthetically active radiation (PAR) measured in 25 plots per habitat.

\begin{tabular}{lllll}
\hline Habitat & \multicolumn{2}{l}{ Distance among canopy trees $(\mathrm{m})$} & & \multicolumn{2}{l}{ PAR radiation $\left(\mu \mathrm{mol} / \mathrm{m}^{2} \mathrm{~s}\right)$} \\
\cline { 2 - 3 } & Mean & CV & Mean & CV \\
\hline Undisturbed & $6.86 \pm 0.45$ & 36.88 & $738.76 \pm 110.53$ & 86.80 \\
Reforested & $2.24 \pm 0.27$ & 27.56 & $50.93 \pm 7.72$ & 49.63 \\
\hline
\end{tabular}


Table 2. Summary of results of point pattern analysis of the spatial patterns of female and hermaphrodite plants. The table shows the $P$-values of goodness of fit tests (Loosmore \& Ford 2006) of 999 simulations of the random labelling null model for several test statistics taken over the distance interval 0-25 m. We analysed the undisturbed and reforested part of the study area separately and together (i.e., entire population). Significant results are in bold.

\begin{tabular}{llll}
\hline Test statistic & Undisturbed & Reforested & Entire population \\
\hline$g_{11}$ & $\mathbf{0 . 0 4 0}$ & 0.963 & 0.213 \\
$g_{12}$ & 0.601 & 0.731 & 0.681 \\
$g_{22}$ & 0.089 & 0.731 & 0.339 \\
$g_{11}-g_{22}$ & $\mathbf{0 . 0 2 5}$ & 0.885 & 0.177 \\
$g_{1,1+2}-g_{2}, 1+2$ & $\mathbf{0 . 0 1 9}$ & 0.743 & 0.213 \\
\hline
\end{tabular}

Although the overall percentage of females was slightly larger in the reforested than in the undisturbed subpopulation (36 and 29\% respectively), the difference was not statistically significant $\left(X^{2}=1.58, p=0.21\right)$. In addition, all significant effects on spatial patterns of female individuals found for the undisturbed subpopulation completely disappeared in the subpopulation located in the reforested area where female and hermaphrodite plants appeared randomly distributed at all distances (Table 2 and Appendix A: Fig. 2). As a consequence, the analysis of the entire population yielded the same tendencies as found for the population in undisturbed habitat but they were not significant at the $5 \%$ level (Table 2).
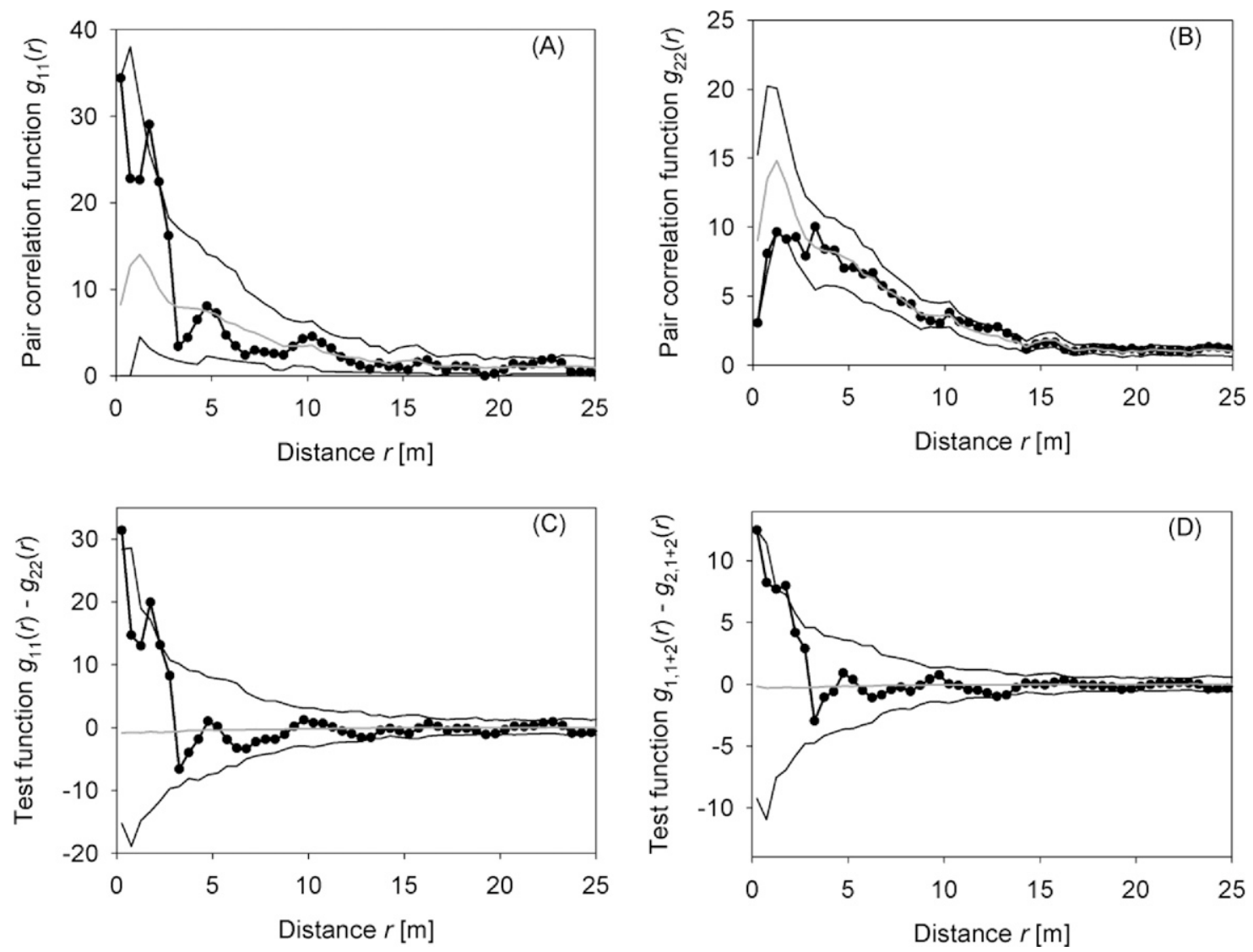

Fig. 2. Spatial patterns of females and hermaphrodites of Daphne laureola in an undisturbed forest area. Univariate pattern in female individuals (A) and bivariate patterns comparing spatial patterns of female and hermaphrodite individuals (B-D). The pair-correlation function of the data is shown as a solid line with closed circles, the expectation of the null models as a solid grey and the simulation envelopes being the 25th smallest and largest values of the 999 simulations of the null model (CSR) as solid black lines. The univariate pattern of females was measured by the statistic $g_{11}(r)$, which tested if the pattern of females was aggregated within the pattern of all plants. Two statistics were calculated to compare the spatial pattern of female and hermaphrodites or bivariate patterns. The first one $\left(g_{11}-g_{22}\right)$ compares the global pattern of female and hermaphrodite plants directly. The second one $\left(g_{1,1+2}-g_{2,1+2}\right)$ compares the density of plants around female individuals with the corresponding density of plants around hermaphrodite individuals. 


\section{Discussion}

Our results revealed different spatial patterning of females in reforested and undisturbed habitats within the Valdecuevas population, whereas the distribution of hermaphrodites followed the random labelling null model in both habitats. In the undisturbed portion of the habitat, female individuals showed an aggregated distribution within short distances of up to $2.5 \mathrm{~m}$, whereas they could not be statistically differentiated from a random sample of all plants within the reforested habitat. Spatial aggregation of sexes has been shown in a few gynodioecious species although the magnitude of such spatial aggregation often varies among species and populations (Graff 1999; Laporte et al. 2001; Olson et al. 2006; van Damme 1986; Van Etten \& Chang 2009). Specifically, spatial aggregation of sexes at short distances (i.e., $2-3 \mathrm{~m}$ ) has been observed in populations of gynodioecious herbaceous species with no dispersal mechanism (Graff 1999; Olson et al. 2006; Van Etten \& Chang 2009). Individual plants of these gynodioecious species (e.g., Sidalcea malviflora, Silene latifolia and Geranium maculatum) are much smaller than individuals of $D$. laureola. Therefore, the spatial aggregation at $2.5 \mathrm{~m}$ found in females of the shrub $D$. laureola implies aggregation in their closest neighbourhood, highlighting the suitability of point pattern analysis in detecting spatial structuring even at small scales as that observed in this study. The short distance over which only $D$. laureola females appeared aggregated is thus intriguing and could eventually arise from at least the three following causes. First, broader ecological amplitude in hermaphrodites than females could generate sex-specific spatial patterning, with hermaphrodites being established randomly in most microhabitats withinpopulation and females only in more specific and narrow microhabitats. Microhabitat for such an understory species would be likely influenced by small-scale soil heterogeneity (Herrera 2002 and references therein) and canopy cover patchiness (Alonso \& Herrera 2008; Vandepitte, RoldánRuiz, Leus, Jacquemyn \& Honnay 2009), which could jointly reduce the scale at which microsites vary. Supporting this notion, the undisturbed habitat within our study population showed higher variability in both overstory structure and light environment of the understory, features which have been shown relevant for the ecological niche segregation in plant species (Valladares et al. 2004). Second, under cytonuclear sex determination, it is expected that most offspring of females are females (McCauley \& Olson 2003), whereas offspring sex ratios from hermaphrodites are more heterogeneous depending on prevalence and diversity of restorer alleles. Repeated feeding on single-seeded fruits from the same plants is likely to produce situations where related individuals will be dispersed in groups (Hamrick \& Nason 1996). Birds can harvest only a few fruits at a time in plant species with large fruits such as D. laureola $(8-10 \times 6-8 \mathrm{~mm})$. Therefore, aggregation over short distance in $D$. laureola females could represent clusters of a few relatives dispersed from the same female mother plant by birds (Olson et al.
2006). Heterogeneity in the sex of hermaphrodites' offspring could in contrast prevent the aggregation of hermaphrodites. Post-dispersal processes (e.g., high mortality around mother plants) could prevent spatial aggregation at a larger scale. Finally, some cryptic and so far undescribed ability for clonal recruitment in $D$. laureola by vegetative multiplication and mortality of intermediate stems, could have led us to consider different ramets of the same genet as different individuals in close vicinity. An eventually increased cloning in females would explain their spatial aggregation within short distances. This hypothesis can be tested with neutral molecular markers that determine if neighbours at two metres from a focal female plant are genetically identical to it (e.g., Vandepitte et al. 2009). Irrespective of its proximate causes, however, the three envisioned mechanisms would require several generations to be reflected in the spatial patterning of reproductive individuals and this could be the reason why in the reforested area the two sexes appeared randomly distributed at all distances.

Ecological changes associated with disturbances may alter the spatial distribution of sexes in a population of a gynodioecious species (McCauley \& Bailey 2009). In particular, preferential establishment and more aggregated distribution of female individuals in disturbed areas have been found in some species (De Cauwer et al. 2010; Manicacci et al. 1996). We found a larger female frequency in reforested than in undisturbed habitat supporting a preferential establishment of female individuals in disturbed areas, although the difference was not statistically significant. Females and hermaphrodites of $D$. laureola did not differ in average seed production in our study area (Alonso \& Herrera 2001; Castilla et al. 2011), although females are relatively more successful in more shaded patches (Alonso \& Herrera 2008) characterizing the reforested area. Furthermore, female progeny is entirely outcrossed in contrast to most hermaphrodite offspring, which present extremely low outcrossing rates (Medrano, Alonso, \& Herrera 2005). Extensive outcrossing in female progeny could favour the incorporation of genetic variants improving slightly colonization ability of females of $D$. laureola, leading to larger abundance of female individuals in disturbed areas. However, we did not find empiric support to stronger spatial structuring of females in disturbed areas in contrast to other gynodioecious species. Rather our results supported canopy forest disturbances erased the spatial distribution of female plants. The absence of spatial structuring of females of $D$. laureola in the reforested habitat could be related to its homogeneously shaded understory where ecological niche segregation is unlikely. Nevertheless, it might also reflect that the spatial patterning of female individuals in $D$. laureola populations requires several generations to emerge.

\section{Conclusions}

Sexes of the shrub $D$. laureola presented differential, disturbance-dependent spatial patterning at a small, 
within-population scale. In the understory of an old mixed forest females were aggregated within all plants at a distance that implies the immediate neighbourhood, whereas hermaphrodites were randomly distributed among all plants. However, this differential patterning disappeared under an adjacent young pine plantation where female plants were slightly more frequent although randomly distributed within all plants. Our results caution against the over-simplification that ecological disturbances lead to stronger spatial structuring of females in gynodioecious species. Rather, our study suggests that the effects of ecological disturbances on the spatial distribution of the sexes depend on the nature of the disturbance and the life-history of the species. However, we must be also cautious with generalizations from our results because of the absence of replication in our study system. Our results point out the existence of spatial patterns different to those widely expected in gynodioecious species, but we will only know the generality of our conclusions with studies considering multiple populations presenting undisturbed and disturbed habitats.

\section{Acknowledgements}

We thank María del Mar Alonso and Mercedes Pérez for their enthusiastic help in the field work. JD Anadon, M Louzao, I Martinez, P Cipriotti, R Jovani, R Kanagaraj and two anonymous reviewers for comments that improved this manuscript; David Aragonés and Ruben Solís, at Laboratory of GIS and Teledetection (LAST-EBD) for assistance with plant mapping; and the Consejería de Medio Ambiente for authorizing our work in Cazorla. This study was funded by the Spanish Ministerio de Educación y Ciencia through research project CGL 2006-01355/BOS, the Consejo Superior de Investigaciones Científicas (CSIC) through an I3P fellowship to A.R.C., which supported a three month visit to the Department of Ecological Modelling at UFZ, Leipzig, and the Consejería de Innovación Ciencia y Empresa, Junta de Andalucía, through the research project RNM156-2005. T.W. was supported by the ERC advanced grant 233066 .

\section{Appendix A. Supplementary data}

Supplementary data associated with this article can be found, in the online version, at http://dx.doi.org/ 10.1016/j.baae.2012.08.005.

\section{References}

Alaback, P. B., \& Herman, F. R. (1988). Long-term response of understory vegetation to stand density in Picea-Tsuga forests. Canadian Journal of Forest Research, 18, 1522-1530.

Alonso, C. (2004). Early blooming's challenges: Extended flowering season, diverse pollinator assemblage, and the reproductive success of gynodioecious Daphne laureola. Annals of Botany, 93, 61-66.

Alonso, C., \& Herrera, C. M. (2001). Neither vegetative nor reproductive advantages account for high frequency of malesteriles in southern Spanish gynodioecious Daphne laureola (Thymelaeaceae). American Journal of Botany, 88, 1016-1024.

Alonso, C., \& Herrera, C. M. (2008). Site-specific features affect pollination success of a gynodioecious understory shrub in a gender-specific mode. Ecoscience, 14, 358-365.

Alonso, C., Mutikainen, P., \& Herrera, C. M. (2007). Ecological context of breeding system variation: Sex, size and pollination in a (predominantly) gynodioecious shrub. Annals of Botany, 100, 1547-1556.

Barbier, S., Gosselin, F., \& Balandier, P. (2008). Influence of tree species on understory vegetation diversity and mechanisms involved - A critical review for temperate and boreal forests. Forest Ecology Management, 254, 1-15.

Bazzaz, F. A. (1990). Plant-plant interactions in succesional environments. In J. B. Grace, \& D. Tilman (Eds.), Perspectives on plant competition (pp. 239-263). San Diego: Academic Press.

Bengtsson, J., Nilsson, S. G., Franc, A., \& Menozzi, P. (2000). Biodiversity, disturbances, ecosystem function and management of European forests. Forest Ecology and Management, 132, 39-50.

Castilla, A. R., Alonso, C., \& Herrera, C. M. (2011). Exploring local borders of distribution in the shrub Daphne laureola: Individual and population traits. Acta Oecologica, 37, 269-276.

Crow, T. R., Buckley, E. A., Nauertz, E. A., \& Zasada, J. C. (2002). Effects of management on the composition and structure of Northern hardwood forests in Upper Michigan. Forest Science, 480, 129-145.

De Cauwer, I., Dufay, M., Fuguen, J., \& Arnaud, J.-F. (2010). Effects of fine-scale genetic structure on male mating success in gynodioecious Beta vulgaris ssp maritima. Molecular Ecology, 19, 1540-1558.

Diggle, P. J. (2003). Statistical analysis of point patterns (2nd ed.). London: Arnold.

El-Klebawy, A., \& Freeman, D. A. (1999). Spatial segregation by gender of the subdioecious shrub Thymelaea hirsuta in the Egyptian desert. International Journal of Plant Science, 160, 341-350.

Eppley, S. M. (2005). Spatial segregation of the sexes and nutrients affect reproductive success in a dioecious wind-pollinated grass. Plant Ecology, 181, 179-190.

Franklin, J. (2010). Spatial point pattern analysis of plants. In L. Anselin, \& S. J. Rey (Eds.), Perspectives on spatial data analysis (pp. 113-271). Berlin/Heidelberg: Springer-Verlag.

Freeman, D. C., Klikoff, L. G., \& Harper, K. T. (1976). Differential resource utilization by the sexes of dioecious plants. Science, 193, 597-599.

Goreaud, F., \& Pélissier, R. (2003). Avoiding misinterpretation of biotic interactions with the intertype K-12-function: Population independence vs. random labelling hypotheses. Journal of Vegetation Science, 14, 681-692.

Graff, A. (1999). Population sex structure and reproductive fitness in gynodioecious Sidalcea malviflora malviflora (Malvaceae). Evolution, 53, 1714-1722.

Greig-Smith, P. (1983). Quantitative plant ecology (3rd ed.). Oxford: Blackwell Scientific.

Hamrick, J. L., \& Nason, J. D. (1996). Consequences of dispersal in plants. In O. E. J. Rhodes, R. K. Chesser, \& M. H. Smith 
(Eds.), Population dynamics in ecological space and time (pp. 203-236). Chicago, IL: University of Chicago Press.

Herrera, C. M. (2002). Topsoil properties and seedling recruitment in Lavandula latifolia: Stage-dependence and spatial decoupling of influential parameters. Oikos, 97, 260-270.

Hill, M. O. (1979). The development of a flora in even-aged plantations. In E. D. Ford, D. C. Malcolm, \& J. Atterson (Eds.), The ecology of even-aged forest plantations (pp. 175-192). Cambridge: Institute of Terrestrial Ecology.

Hulme, P. E. (1992). The ecology of a temperate plant in a Mediterranean environment: Post-dispersal seed predation of Daphne laureola. In C. A. Thanos (Ed.), Plant-animal interactions in mediterranean-type ecosystems (pp. 281-286). Athens, Greece: University of Athens.

Illian, J., Penttinen, A., Stoyan, H., \& Stoyand, D. (2008). Statistical analysis and modelling of spatial point patterns. Chichester: John Wiley \& Sons.

Jacquemyn, H., Endels, P., Honnay, O., \& Wiegand, T. (2010). Spatio-temporal analysis of seedling recruitment, mortality and persistence into later life stages in the rare Primula vulgaris. Journal of Applied Ecology, 47, 431-440.

Jennings, S. B., Brown, N. D., \& Sheil, D. (1999). Assessing forest canopies and understory illumination: Canopy closure, canopy cover and other measures. Forestry, 61, 317-338.

Kirby, K. J. (1988). Changes in the ground flora under plantations on ancient woodland sites. Forestry, 61, 317-338.

Laporte, V., Viard, F., Bena, G., Valero, M., \& Cuguen, J. (2001). The spatial structure of sexual and cytonuclear polymorphism in the gynodioecious Beta vulgaris ssp maritima: I/at a local scale. Genetics, 157, 1699-1710.

Loosmore, N. B., \& Ford, E. D. (2006). Statistical inference using the $\mathrm{g}$ or K point pattern spatial statistics. Ecology, 87, 1925-1931.

Manicacci, D., Couvet, D., Belhassen, E., Gouyon, P.-H., \& Atlans, A. (1996). Founder effects and sex ratio in the gynodioecious Thymus vulgaris L. Molecular Ecology, 5, 63-72.

McCauley, D. E., \& Bailey, M. F. (2009). Recent advances in the study of gynodioecy: The interface of theory and empiricism. Annals of Botany, 104, 611-620.

McCauley, D. E., \& Olson, M. S. (2003). Associations among cytoplasmic molecular markers, gender, and components of fitness in Silene vulgaris, a gynodioecious plant. Molecular Ecology, 12, 777-787.

McIntire, E. J. B., \& Fajardo, A. (2009). Beyond description: The active and effective way to infer processes from spatial patterns. Ecology, 90, 46-56.

Medrano, M., Alonso, C., \& Herrera, C. M. (2005). Mating system, sex ratio, and persistence of females in the gynodioecious shrub Daphne laureola L. (Thymelaeaceae). Heredity, 94, 37-43.

Miyake, K., \& Olson, M. S. (2009). Experimental evidence for frequency dependent self fertilization in the gynodioecious plant Silene vulgaris. Evolution, 63, 1644-1652.

Niemelä, J. (1999). Management in relation to disturbance in the boreal forest. Forest Ecology and Management, 115, 127-134.
Obeso, J. R. (1985). Comunidades de pájaros y frugivorismo en altitudes medias de la Sierra de Cazorla. Ph.D. Thesis. Oviedo, Spain: University of Oviedo.

Olson, M. S., Graf, A. V., \& Niles, K. R. (2006). Fine scale spatial structuring of sex and mitochondria in Silene vulgaris. Journal of Evolutionary Biology, 19, 1190-1201.

Pielou, E. C. (1968). An introduction to mathematical ecology. New York: Wiley.

Ripley, B. D. (1981). Spatial statistics. New York: Wiley.

Schurr, F. M., Bossdorf, O., Milton, S. J., \& Schumacher, J. (2004). Spatial pattern formation in semi-arid shrubland: A priori predicted versus observed pattern characteristics. Plant Ecology, 173, 271-282.

Stoyan, D., \& Stoyan, H. (1994). Fractals, random shapes and point fields. Methods of geometrical statistics. Chichester: Wiley \& Sons.

Thomas, S. C., Halpern, C. B., Falk, D. A., Liguori, D. A., \& Austin, K. A. (1999). Plant diversity in managed forests: Understory responses to thinning and fertilization. Ecological Applications, 9, 864-879.

Valladares, F., Aranda, I., \& Sánchez-Gómez, D. (2004). La luz como factor ecológico y evolutivo para las plantas y su interacción con el agua. In F. Valladares (Ed.), Ecologia del bosque mediterráneo en un mundo cambiante (pp. 335-369). EGRAF, S.A., Madrid: Ministerio de Medio Ambiente.

Valladares, F., \& Gianoli, E. (2007). How much ecology do we need to know to restore Mediterranean Ecosystems? Restoration Ecology, 15, 363-368.

van Damme, J. M. M. (1986). Gynodioecy in Plantago lanceolata L. V. Frequencies and spatial distribution of nuclear and cytoplasmic genes. Heredity, 56, 355-364.

Van Etten, M. L., \& Chang, S.-M. (2009). Effects of environmental heterogeneity on the distribution of sexes within and among populations in a gynodioecious species, Geranium maculatum. New Phytologist, 183, 649-660.

Vandepitte, K., Roldán-Ruiz, I., Leus, L., Jacquemyn, H., \& Honnay, O. (2009). Canopy closure shapes clonal diversity and fine-scale genetic structure in the dioecious understory perennial Mercurialis perennis. Journal of Ecology, 97, 404-414.

Watt, A. S. (1947). Pattern and processes in the plant community. Journal of Ecology, 35, 1-22.

Wiegand, T., \& Moloney, K. A. (2004). Rings, circles and nullmodels for point pattern analysis in ecology. Oikos, 104, 209-229.

Wiegand, T., Martinez, I., \& Huth, A. (2009). Recruitment in tropical species: Revealing complex spatial patterns. American Naturalist, 174, E106-E140.

Wiegand, T., Jeltsch, F., Hanski, I., \& Grimm, V. (2003). Using pattern oriented modelling for revealing hidden information: A key for reconciling ecological theory and application. Oikos, 100, 209-222.

Yu, H., Wiegand, T., Yang, X., \& Ci, L. (2009). The impact of fire and density-dependent mortality on the spatial patterns of a pine forest in the Hulun Buir sandland, Inner Mongolia, China. Forest Ecology and Management, 257, 2098-2107. 